\title{
Systemic tranexamic acid promotes bone healing in a rat model of femur fracture
}

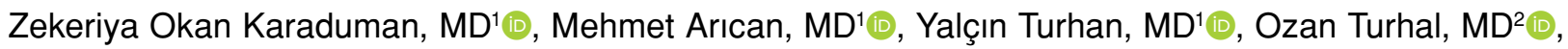 \\ Zafer Orhan, MD' ${ }^{1}$, Mehmet Gamsızkan, MD $^{3}$ (D) \\ ${ }^{1}$ Department of Orthopedics and Traumatology, Düzce University, Faculty of Medicine, Düzce, Turkey \\ 2Department of Orthopedics and Traumatology, Düzce State Hospital, Düzce, Turkey \\ ${ }^{3}$ Department of Pathology, Düzce University, Faculty of Medicine, Düzce, Turkey
}

Fracture healing is a complex process that requires a local hematoma rich in mesenchymal cells and cytokines. ${ }^{[1]}$ Despite the study of several factors that may affect this process and advances in this field, the process of fracture healing has not been fully elucidated. ${ }^{[2]}$ Fracture healing begins with the accumulation of blood from bone, periosteum, and surrounding soft tissues in the fracture site. This period is known as the hematoma phase and lasts approximately one-two days. ${ }^{[3]}$ Inflammatory mediators released from platelets and dead or injured cells cause blood vessels to dilate, leading to the leakage of plasma toward the acute edema observed at the fracture site. Macrophages, lymphocytes, and fragmented leukocytes migrate to this region. These cells also secrete cytokines that stimulate vascularization. Some agents like locally administered icariin facilitates bone healing via

Received: April 14, 2020

Accepted: June 05, 2020

Published online: June 24, 2020

Correspondence: Zekeriya Okan Karaduman, MD. Düzce Üniversitesi Tıp Fakültesi Ortopedi ve Travmatoloji Anabilim Dalı, 81110 Düzce, Türkiye.

E-mail: karadumano@hotmail.com

Doi: $10.5606 /$ ehc. 2020.75430

Citation: Karaduman ZO, Arıcan M, Turhan Y, Turhal O, Orhan Z, Gamsızkan M. Systemic tranexamic acid promotes bone healing in a rat model of femur fracture. Jt Dis Relat Surg 2020;31(3):432-439.

(92020 All right reserved by the Turkish Joint Diseases Foundation

This is an open access article under the terms of the Creative Commons Attribution-NonCommercial License, which permits use, distribution and reproduction in any medium, provided the original work is properly cited and is not used for commercial purposes (http://creativecommons.org/licenses/by-nc/4.0/).

\section{ABSTRACT}

Objectives: This study aims to investigate the effect of tranexamic acid (TXA) on the union of closed femoral fractures using radiological and histological methods in an experimental rat model.

Materials and methods: This experimental study was conducted between June 2017 and February 2018. Closed femoral fractures were created in 36 male Wistar albino rats (age: three months [range, 2.5-3.5 months], weighing 200 grams [range, 180-220 grams]). Half of the animals randomly divided into two groups were administered intravenous single dose of TXA $(30 \mathrm{mg} / \mathrm{kg})$, whereas the animals in the control group did not receive any medication. The animals in the two groups were randomly divided into three groups with six animals each and cervical dislocation was performed at days 15 , 30 , and 45 , and radiological and histopathological healing scores were compared.

Results: When the mean radiological scores of the TXA and control groups were compared, a statistically significant difference was found in favor of the TXA group at day $15(\mathrm{p}=0.019)$, but no significant difference was found in the mean scores on days 30 and 45 ( $\mathrm{p}=0.138$ and $\mathrm{p}=0.269$, respectively). Histopathological examination also showed a statistically significant difference between the 15-day mean score values in favor of the TXA group $(\mathrm{p}=0.017)$.

Conclusion: The use of systemic TXA accelerates early bone formation and fracture healing.

Keywords: Experimental rat model, fracture healing, tranexamic acid.

improving antioxidant responses within the fracture site. ${ }^{[4]}$ When the inflammatory response begins to diminish, necrotic tissue and exudate are reabsorbed, and fibroblasts and chondrocytes emerge and begin to produce the new matrix and fracture callus. ${ }^{[5]}$ Fracture hematoma acts as a skeleton made of fibrin to facilitate the activity of repair cells. In addition, platelets and other cells in the fracture hematoma lead 
to the release of growth factors together with other proteins [epidermal growth factor, fibroblast growth factor, platelet-derived growth factor, transforming growth factor-beta (TGF- $\beta$ ), bone-derived growth factor, and interleukin-1] release. These factors and proteins are essential for cell migration, periosteal cell proliferation, and the synthesis of repair tissue matrix, which are important in fracture healing. ${ }^{[6]}$

Tranexamic acid (TXA) (trans-4-aminomethylcyclohexane-1-carboxylic acid) is a synthetic lysine analog antifibrinolytic drug with low molecular weight. ${ }^{[7]}$ It promotes clotting through inhibition of fibrinolysis by inhibiting the activation of plasmin/ plasminogen. ${ }^{[8]}$ Thus, it forms a reversible complex with plasminogen and plasmin. It also helps to preserve platelet function by inhibiting plasmiddependent platelet activation. ${ }^{[9]}$

In the last 10 years, TXA has been frequently used in orthopedics and traumatology surgery for ailments such as pelvic fractures, including total knee and hip arthroplasties that cause major blood loss. ${ }^{[10]}$ Also, previous studies on TXA mainly focused on its effect on blood. This study investigated its effect on bone healing. Thus, that is the novelty of this study. It can be considered that TXA prevents the dissolution of the fracture hematoma at the fracture site and keeps the inflammatory mediators, growth factors, and fibroblasts necessary for fracture healing at the fracture site, thereby accelerating fracture healing. Therefore, in this study, we aimed to investigate the effect of TXA on the union of closed femoral fractures using radiological and histological methods in an experimental rat model.

\section{MATERIALS AND METHODS}

A total of 36 male Wistar albino rats (age: three months [range, 2.5-3.5 months], weighing 200 grams [range, 180-220 grams]) (Abant Izzet Baysal University Faculty of Medicine Experimental Research Laboratory, Bolu) were used in this experimental study conducted between June 2017 and February 2018. Prior to the study, required permissions were obtained from Abant Izzet Baysal University Experimental Animals Ethics Committee (No: 201735/2017). The rats included in the study were preoperatively monitored for 48 hours in the laboratory. During the study, rats were allowed to access unlimited water and food (ad libitum). The animals were monitored at $22^{\circ} \mathrm{C}$ with a 12 -hour daynight cycle.

Anesthesia was induced by single dose intramuscular ketamine (Ketalar; Pfizer, Istanbul, Turkey)/xylazine (Rompun; Bayer, Leverkusen, Germany) combination $(90 / 10 \mathrm{mg} / \mathrm{kg})$. Following anesthesia, right anterior thigh regions of the rats were trimmed and prepped with $10 \%$ povidone iodine (Batticon; Adeka, Samsun, Turkey). A $1 \mathrm{~cm}$ longitudinal skin incision was performed at the level of the right knee joint. The patella was then laterally deviated with a medial parapatellar incision to expose the distal femoral condyle, and the Kirchner $(\mathrm{K})$ wire ( $1 \mathrm{~mm}$ in diameter) was retrog radely delivered to the intramedullary canal. Subsequently, the patella was reduced and subcutaneous tissues were closed with absorbable suture, and skin incision was closed with non-absorbable suture. Antibiotic prophylaxis was not performed in any rat. Following surgery, guillotine
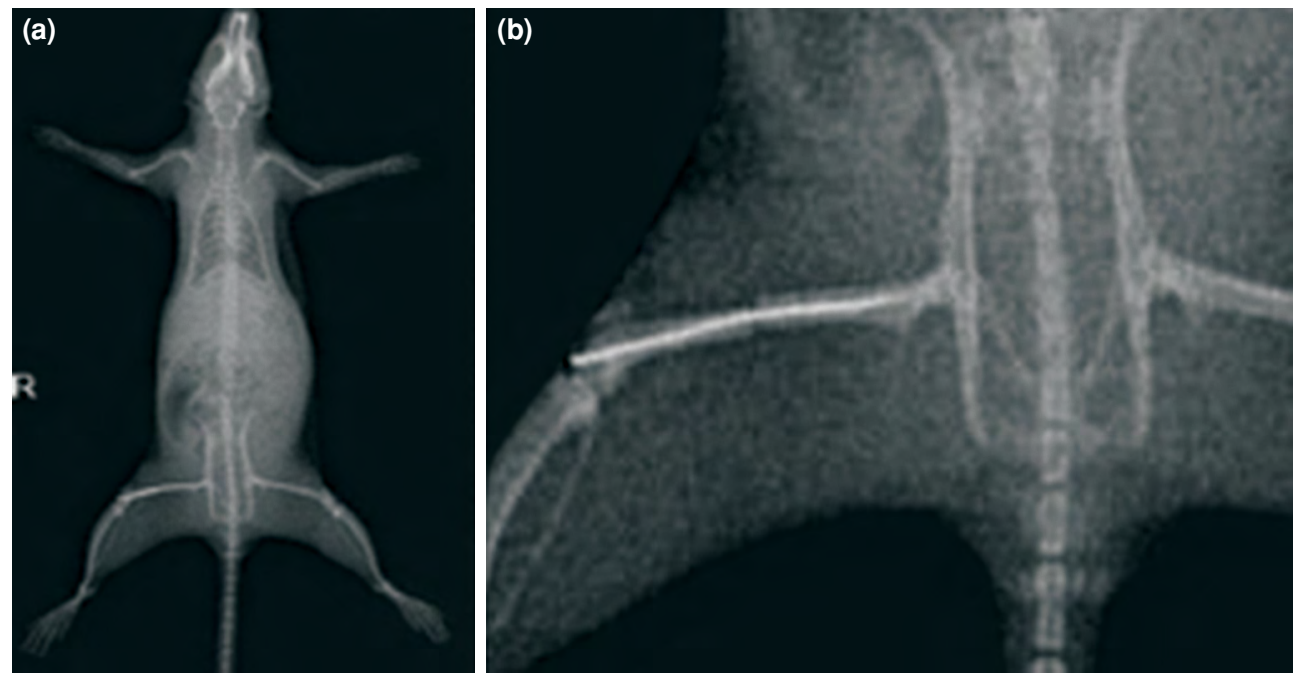

FIGURE 1. (a, b) Radiographic confirmation of fracture and fixation. 


\begin{tabular}{|llll|}
\hline & \multicolumn{3}{c}{ TABLE I } \\
& Distribution of tranexamic acid and control groups & \\
\hline Groups & Week 2 sacrification & Week 4 sacrification & Week 6 sacrification \\
\hline TXA experimental groups & TXA group 1 & TXA group 2 & TXA group 3 \\
Control groups & Control group 1 & Control group 2 & Control group 3 \\
\hline TXA; Tranexamic acid. & & & \\
\hline
\end{tabular}

method was applied and a transverse fracture line was created in the mid-diaphysis area of the femur. The fracture was then confirmed by control X-ray (Figure 1). The rats were then randomly divided into six groups:

- Control group 1: No drug was administered and cervical dislocation was performed at the end of week two.

- TXA group 1: Single dose of intravenous (IV) TXA $(30 \mathrm{mg} / \mathrm{kg})$ was administered via dorsal tail vein after surgical procedure, ${ }^{[11]}$ and cervical dislocation was performed at the end of week two.

- Control group 2: No drug was administered, and cervical dislocation was performed at the end of week four.
- TXA group 2: Single dose of IV TXA $(30 \mathrm{mg} / \mathrm{kg})$ was administered via dorsal tail vein after surgical procedure, ${ }^{[11]}$ and cervical dislocation was performed at the end of week four.

- Control group 3: No drug was administered, and cervical dislocation was performed at the end of week six.

- TXA group 3: Single dose of IV TXA $(30 \mathrm{mg} / \mathrm{kg}$ ) was administered via dorsal tail vein after surgical procedure, ${ }^{[11]}$ and cervical dislocation was performed at the end of week six (Table I).

Euthanasia was performed by cervical dislocation. After the procedure, the right femurs of the rats
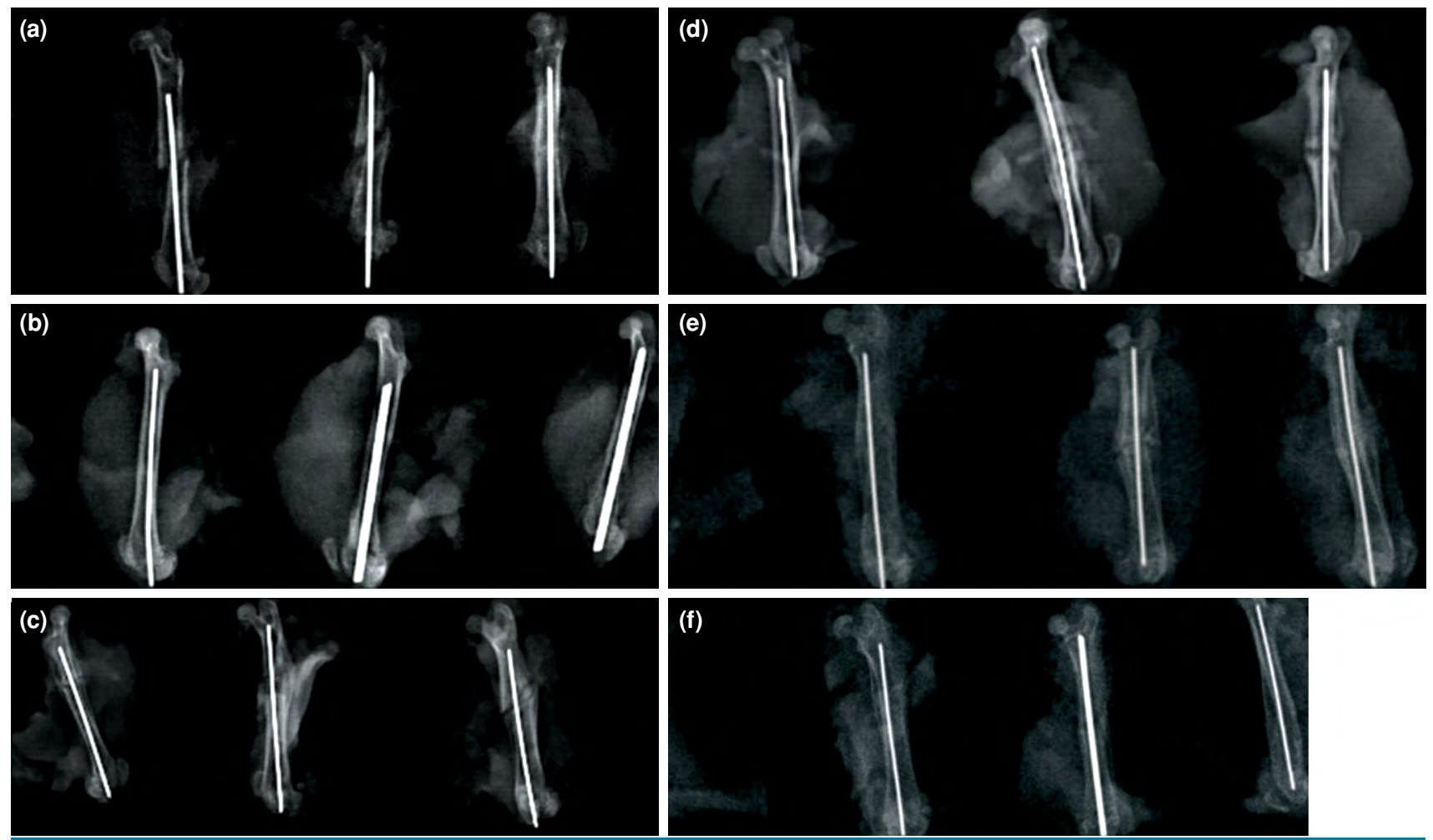

FIGURE 2. Radiological evaluation of fracture healing at 15,30 , and 45 days. (a, c, e) Control group; (b, d, f) Tranexamic acid group. 


\begin{tabular}{|cl|}
\multicolumn{3}{c|}{ TABLE II } \\
Score & Histological scoring system for fracture healing ${ }^{[13]}$ \\
\hline 1 & Fibrous tissue \\
2 & Mainly fibrous tissue and small amount of cartilage \\
& tissue \\
3 & Equal amount of fibrous and cartilage tissue \\
4 & Completely cartilage tissue \\
5 & Mainly cartilage tissue and small amount of imma- \\
& ture bone \\
6 & Equal amount of cartilage tissue and immature bone \\
7 & Significantly immature bone and small amount of \\
& cartilage \\
8 & Completely immature bone \\
9 & Immature bone and small amount of mature bone \\
10 & Mature bone
\end{tabular}

were disarticulated from the hip and knee joints and removed. The soft tissues on the femur were gently stripped from the bone without damaging the callus tissue, and radiological examination of the bone tissue was performed. The samples were then subjected to histopathological examination.

Anteroposterior and lateral X-ray images of the femurs were obtained after cervical dislocation (Figure 2). Fracture healing was evaluated in a blinded manner by an independent orthopedic surgeon using the radiological scoring system described by Lane and Sandhu ${ }^{[2]}$ scoring based on this system was as follows: 0 , no healing; 1 , callus formation; 2 , onset of bone union; 3 , fracture line beginning to disappear; and 4 , complete bone union.

After radiological imaging, $\mathrm{K}$ wires inside the femoral intramedullary canal were carefully removed without damaging the callus tissue. Bone tissues were then fixed in $4 \%$ paraformaldehyde at $4^{\circ} \mathrm{C}$ for 48 hours and then decalcified in $10 \%$ formic acid. After decalcification, the samples were embedded in paraffin blocks and $6 \mu \mathrm{m}$ sections were obtained. Hematoxylin-eosin and Masson's trichrome staining were performed, and the sections were histopathologically evaluated using the scoring system proposed by Huo et al., ${ }^{[13]}$ (Table II).

\section{Statistical analysis}

The data were statistically analyzed using the Number Cruncher Statistical System 2007 statistical software (NCSS, Utah, USA). In addition to descriptive statistical methods (mean, standard deviation, median, interquartile range), Kruskal-Wallis test was used for multiple group comparisons, Dunn's multiple comparison test was used for multiple sub-group comparisons, and Mann-Whitney $\mathrm{U}$ test was used for comparison of two groups. $\mathrm{P}<0.05$ was accepted as statistically significant in all analyses.

\section{RESULTS}

No animals were lost at any stage of the study, and no wound infection was observed in any rat during the follow-up period.

In the radiological examination, the mean scores of the control group were 0.33 on day 15,0 on day 30 , and 3.33 on day 45 . The comparison of these results revealed a statistically significant difference $(p=0.0001)$. Dunn's multiple comparison test revealed a significant difference between day 15 and day 45 $(p=0.001)$. The examination of the radiological results of the TXA group revealed that the mean scores were 1 on day $15,2.33$ on day 30 , and 3.67 on day

\begin{tabular}{|c|c|c|c|c|c|}
\hline Radiological scor & $\begin{array}{l}\mathrm{CAB} \\
\operatorname{grc}\end{array}$ & t days 15 & and & & \\
\hline & & group & & oup & \\
\hline & $\mathrm{n}$ & $\%$ & $\mathrm{n}$ & $\%$ & \\
\hline Day 15 & & & & & 0.03 \\
\hline No healing & 4 & 66.67 & 0 & 0.00 & \\
\hline Callus formation & 2 & 33.33 & 6 & 100.00 & \\
\hline Onset of bone union & 6 & 100.00 & 4 & 66.67 & \\
\hline Day 30 & & & & & 0.227 \\
\hline Fracture line beginning to disappear & 0 & 0.00 & 2 & 33.33 & \\
\hline Fracture line beginning to disappear & 4 & 66.67 & 2 & 33.33 & \\
\hline Day 45 & & & & & 0.284 \\
\hline Complete bone union & 2 & 33.33 & 4 & 66.67 & \\
\hline$p$ & & & & & \\
\hline
\end{tabular}




\begin{tabular}{|c|c|c|c|}
\hline \multicolumn{4}{|c|}{$\begin{array}{r}\text { TABLE IV } \\
\text { Histopathological scores by groups }\end{array}$} \\
\hline & $15^{\text {th }}$ day & $30^{\text {th }}$ day & $45^{\text {th }}$ day \\
\hline Control group 1 & 3 & 4 & 9 \\
\hline Control group 2 & 2 & 5 & 4 \\
\hline Control group 3 & 2 & 4 & 10 \\
\hline Control group 4 & 4 & 8 & 10 \\
\hline Control group 5 & 3 & 9 & 6 \\
\hline Control group 6 & 3 & 4 & 9 \\
\hline TXA group 1 & 4 & 9 & 10 \\
\hline TXA group 2 & 4 & 8 & 10 \\
\hline TXA group 3 & 3 & 5 & 9 \\
\hline TXA group 4 & 4 & 9 & 10 \\
\hline TXA group 5 & 3 & 8 & 10 \\
\hline TXA group 6 & 4 & 7 & 8 \\
\hline
\end{tabular}

$45(\mathrm{p}=0.001)$. The comparison of the mean scores in the TXA and control groups revealed a statistically significant difference on day $15(\mathrm{p}=0.019)$; however, there was no significant difference between the groups on days 30 and $45(\mathrm{p}=0.138$ and $\mathrm{p}=0.269$, respectively) (Table III).

In the histopathological examination, mean scores of the control group were 2.83 on day $15,5.97$ on day 30 , and 8.00 on day 45 ( $p=0.001$ ). Dunn's multiple comparison test revealed a significant difference between day 15 and day $45(\mathrm{p}<0.001)$. In the TXA group, the mean scores were 3.66 on day $15,5.0$ on day 30 , and 8.15 on day 45 ( $p=0.017$ ). Dunn's multiple comparison test revealed a significant difference between day 15 and day $45(\mathrm{p}<0.001)$ (Table 4, Figures $3 a, b$ and $4 a, b)$.

When the groups were compared among themselves, a statistically significant difference was observed between day 15 scores $(p=0.019)$. However, there was no statistically significant difference between the groups on day 15 and day 45 ( $p=0.863$ and $\mathrm{p}=0.615$, respectively).

\section{DISCUSSION}

The present study investigating the effect of TXA on femoral fracture healing found that TXA accelerated early bone formation and fracture healing compared with the control group. In radiographic examinations, bone healing scores of rats in the TXA treatment group were significantly better than those in the control group on day 15. Tranexamic acid treatment was found to be extremely effective in improving both new bone and callus formation. Although radiological scores of bone formation of the TXA group were higher on day 15, there was no significant difference between the two groups on days 30 and 45 . This may occur because the effects of the inflammation process for new bone formation are more significant on day 15 . Union and remodeling occurs after callus formation; thus, the radiological scores for union and remodeling were almost identical in both groups. These findings support the hypothesis that TXA leads to accelerated bone formation but has no significant effect on final union or remodeling. According to histopathological scores, there was a significant difference between TXA and control groups on day 15. The resulting fibrous and cartilage tissues formed in the early stages of bone healing, leading to the development
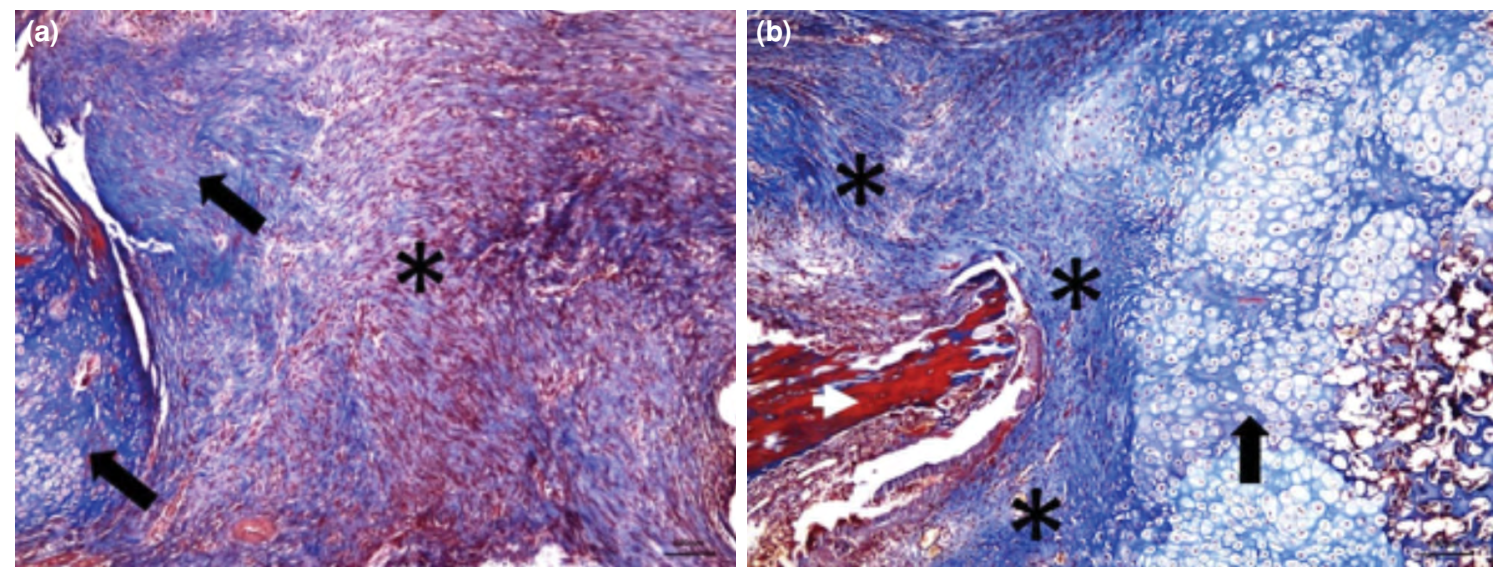

FIGURE 3. (a) Predominantly fibrous tissue (asterisk: fibrous tissue, arrow: chondroid tissue), numeric scores 2 points (Masson's trichrome, x100). (b) Equal amount of fibrous and cartilage tissue (asterisk: fibrous tissue, arrow: chondroid tissue, white arrow head: normal entrapped bone), 3 points (Masson's trichrome, x100). 


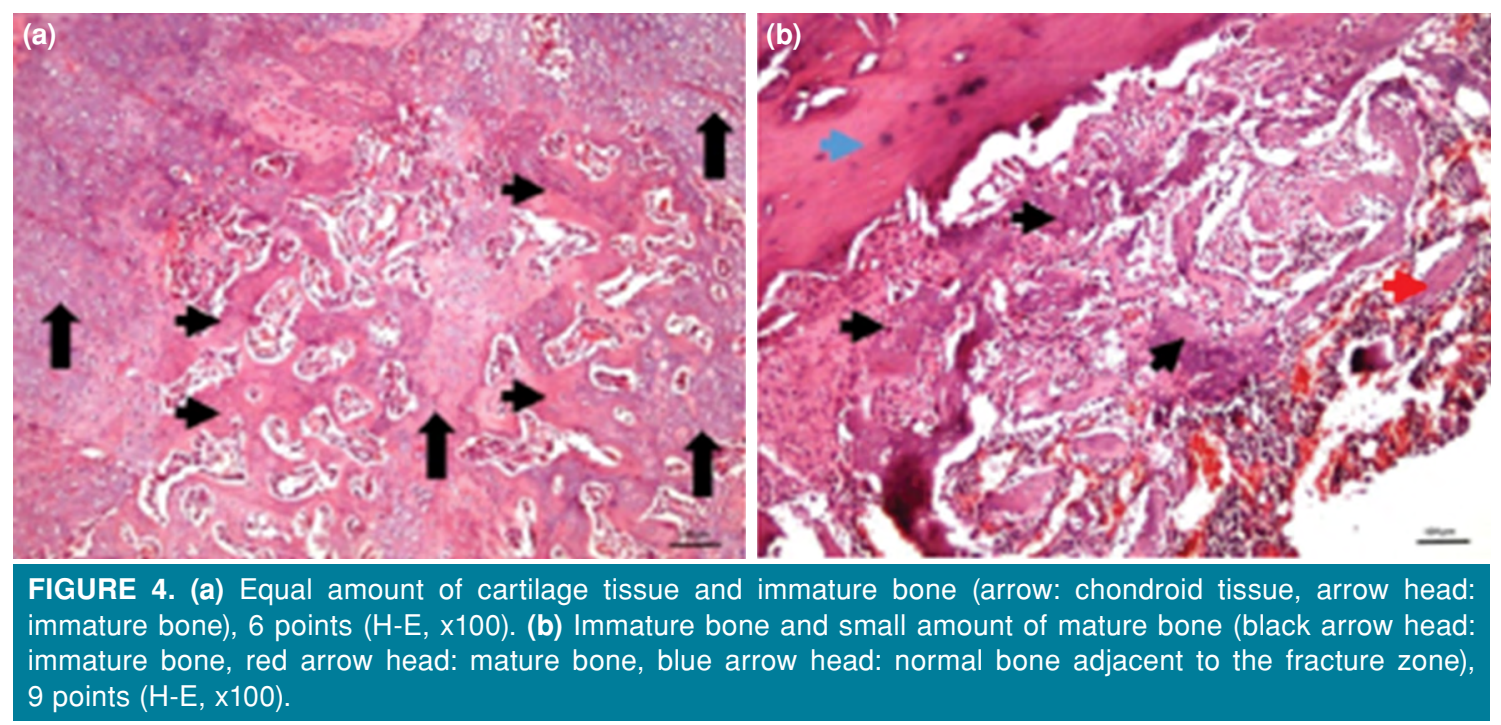

of immature bone. The effects of TXA on bone formation were significant in the early stages of recovery. Histopathological findings showed that TXA treatment increased bone healing via intensive callus formation.

Fracture healing was radiologically and histologically examined in the following three periods: the inflammatory period, the repair period, and the remodelization period. ${ }^{[14]}$ Fracture healing is a complex process that requires a local hematoma rich in mesenchymal cells and cytokines. ${ }^{[15]}$ There is a strong correlation between angiogenesis and osteogenesis during fracture healing. ${ }^{[16]}$ The transport of biomaterials to the fracture site through blood is necessary for adequate and rapid recovery, and the process of converting the organized hematoma into bone callus involves the endochondral and intramembranous ossification stages. In addition, chondrocyte differentiation and mineralization require adequate nutrition from the vascular bed. ${ }^{[17]}$

Tranexamic acid, a lysine analog, primarily inhibits the activation of plasmin/plasminogen and promotes coagulation by inhibition of fibrinolysis. ${ }^{[7]}$ Tranexamic acid, a low molecular weight synthetic antifibrinolytic drug, binds to the lysine binding sites of plasmin and plasminogen that bind to the fibrin molecule, forming a reversible complex with plasminogen and plasmin. Consequently, plasmin cannot bind to fibrinogen or other monomers and inhibition of fibrinolysis occurs. ${ }^{[8]}$ It also protects platelet functions by inhibiting plasmid-dependent platelet activation. ${ }^{[9]}$ Blood loss and subsequent transfusions are associated with major morbidity and mortality. Antifibrinolytic use may reduce blood loss in cardiac surgery, trauma, orthopedic surgery, liver surgery and solid organ transplantation, obstetrics and gynecology, and neurosurgical interventions. ${ }^{[18]}$

The effects of several substances on fracture healing have been examined in the literature. An animal model study by Gürbüz et al. ${ }^{[4]}$ showed that pentoxifylline accelerated fracture healing in the early period and delayed histological union in the late period in rats. As a result of radiological findings, pentoxifylline use was found to be ineffective on fracture healing. In our study, we histologically and radiologically demonstrated that TXA accelerates fracture healing in the early period. In a rat model developed by Baldık et al., ${ }^{[19]}$ it was radiologically and histologically shown that nitric oxide increased bone healing in the early period by increasing cartilage callus tissue. In our study, TXA also increased callus tissue in the early period. Street et al. ${ }^{[20]}$ showed that vascular endothelial growth factor locally applied to the fracture site accelerated both angiogenesis and fracture healing. This supports early fracture healing observed in our study with the effect of proteins found in fracture hematoma. Le Guehennec et al. ${ }^{[21]}$ reported that the antifibrinolytic agent aprotinin was extremely important for bone colonization of a stable fibrin skeleton. They observed that there was less bone development in low calcium chloride and low aprotinin groups. In our study, we demonstrated both histologically and radiologically that TXA, an antifibrinolytic agent similar to aprotinin, preserved fibrin roof for a longer period on 
day 15 compared with the control group. In the 2012 meta-analysis, Yang et al. ${ }^{[22]}$ showed that the use of TXA was effective and safe in reducing blood loss in patients undergoing total knee arthroplasty.

By inhibiting the proteolytic effect of plasmin, TXA inhibits the fibrinolytic system, stabilizes clot formation, and reduces blood loss. This supports our hypothesis that TXA accelerates fracture healing in the early period by preserving the fracture hematoma. In a study examining the effect of neurokinin-1-receptor blockade on fracture healing in rats, ${ }^{[23]}$ it was demonstrated that neurokinin-1-receptor blockade suppressed gene expression of important proteins during early fracture healing, reduced the quality of the callus formed, and reduced the biomechanical strength of the bone formed in the late fracture phases. In our study, we showed that stabilization of the fracture hematoma leading to preservation of important proteins in the early stages of fracture healing increased early callus formation. In a 2019 study, Buarque de Gusmão et al. ${ }^{[24]}$ examined the effect of extracorporeal shock-wave therapy (ESWT) on bone morphogenetic protein (BMP)-2, extracellular signal-regulated kinase-2, focal adhesion kinase, and TGF- $\beta 1$ and found that ESWT increased the stimulation of these proteins in the early period and increased fracture healing by inducing early callus formation. In our study, we consider that the increase in early callus formation by TXA occurs through the preservation of proteins present in the fracture hematoma. Akyildiz et al. ${ }^{[25]}$ showed that platelet-rich plasma increased the formation of cartilage callus in the early period; in our study, we also found that cartilage callus formation increased in the early period. In an experimental study, ${ }^{[26]}$ it was shown that growth factors administered to the fracture site increased fracture healing biomechanically and histologically. As the growth factors found in the fracture hematoma were preserved in our study, recovery was found to be quicker in the early callus period in the TXA group. Schoenecker et al. ${ }^{[27]}$ studied aprotinin and aminocaproic acid in vitro in osteoclast cell cultures, and found that the therapeutic dose of aprotinin inhibited the proteolytic activity of plasmin in a dose-dependent manner while stimulating osteoblast proliferation and inhibiting osteoblast differentiation and matrix mineralization. It was reported that the same effect (inhibition of osteoblast differentiation and matrix mineralization of aprotinin) could be reversibly obtained by removing aprotinin from the culture and stimulating the cells with BMP-2 or plasmin.
In contrast, the inhibition of proteolytic activity of plasmin by aminocaproic acid was significantly weaker than that by aprotinin, whereas it had no effect on osteoblast proliferation, differentiation, or matrix mineralization in the therapeutic range.

Antifibrinolytics are divided into two groups based on their mechanism of action: the first group consists of protease inhibitors-antifibrinolytics, which inhibit the proteolytic activity of plasmin (aprotinin), and the second group consists of binding inhibitors-antifibrinolytics (aminocaproic acid and TXA) blocking fibrinolytic binding. In our study, although TXA probably had a similar mechanism of action to that of aminocaproic acid, it was found to affect fracture healing radiologically and histologically. Çıraklı et al. ${ }^{[28]}$ investigated the effect of TXA on tendon healing and found that TXA applied locally had a negative effect on tendon healing in the late period. In our study, we found no negative effect on fracture healing in the late stages compared with the control group. Xie et al. ${ }^{[29]}$ conducted a study to evaluate the effect of TXA on the reduction of postoperative blood loss in internal fixation and bone graft open reduction applications in calcaneus fractures, and reported that there was no significant difference between the TXA and control groups in terms of intraoperative blood loss. However, in the TXA group, postoperative blood loss during the first 24 hours was reported to be significantly lower than that in the control group, whereas the incidence of wound complications was also lower than that in the control group. There was no significant difference in the incidence of thromboembolic events or adverse drug reactions between the two groups. They concluded that preoperative single dose TXA administration could effectively reduce postoperative blood loss and wound complications in calcaneal fractures and did not develop any significant side effect when compared with the control group. Consequently, it can be safely used in fractures owing to its effect on both blood loss and union.

A limitation of our study was the lack of different TXA doses. Further in vivo and in vitro studies are needed to obtain more information on the effects of TXA.

In conclusion, we found that the use of systemic TXA accelerates early bone formation and fracture healing. Both radiological and histological differences were detected in the early period. We hope that more studies will be conducted on this subject, and other biochemical and biomechanical 
parameters that could not be investigated in this study will be assessed.

\section{Acknowledgement}

We acknowledge all the researchers who have determined the effect of fracture healing in this experimental model.

\section{Declaration of conflicting interests}

The authors declared no conflicts of interest with respect to the authorship and/or publication of this article.

\section{Funding}

This research was supported by grants from the Scientific Research Projects Unit of Duzce University, Duzce, Turkey (2018.4.2.666).

\section{REFERENCES}

1. Yin ZY, Yin J, Huo YF, Yu J, Sheng LX, Dong YF. Rapamycin facilitates fracture healing through inducing cell autophagy and suppressing cell apoptosis in bone tissues. Eur Rev Med Pharmacol Sci 2017;21:4989-98.

2. McKibbin B. The biology of fracture healing in long bones. J Bone Joint Surg [Br] 1978;60:150-62.

3. Einhorn TA, Majeska RJ, Rush EB, Levine PM, Horowitz $\mathrm{MC}$. The expression of cytokine activity by fracture callus. J Bone Miner Res 1995;10:1272-81.

4. Gürbüz K, Yerer MB, Gürbüz P, Halıcı M. Icariin promotes early and late stages of fracture healing in rats. Eklem Hastalik Cerrahisi 2019;30:282-8.

5. Kolar P, Gaber T, Perka C, Duda GN, Buttgereit F. Human early fracture hematoma is characterized by inflammation and hypoxia. Clin Orthop Relat Res 2011;469:3118-26.

6. Marsell R, Einhorn TA. The biology of fracture healing. Injury 2011;42:551-5.

7. Dunn CJ, Goa KL. Tranexamic acid: a review of its use in surgery and other indications. Drugs 1999;57:1005-32.

8. Hoylaerts M, Lijnen HR, Collen D. Studies on the mechanism of the antifibrinolytic action of tranexamic acid. Biochim Biophys Acta 1981;673:75-85.

9. Roy M, Burggraf M, Lendemans S, de Groot H, Rohrig R. Tranexamic acid prolongs survival after controlled hemorrhage in rats. J Surg Res 2017;208:104-10.

10. Lier H, Maegele M, Shander A. Tranexamic Acid for Acute Hemorrhage: A Narrative Review of Landmark Studies and a Critical Reappraisal of Its Use Over the Last Decade. Anesth Analg 2019;129:1574-84.

11. Roy M, Burggraf M, Lendemans S, de Groot H, Rohrig R. Tranexamic acid prolongs survival after controlled hemorrhage in rats. J Surg Res 2017;208:104-10.

12. Lane JM, Sandhu HS. Current approaches to experimental bone grafting. Orthop Clin North Am 1987;18:213-25.

13. Huo MH, Troiano NW, Pelker RR, Gundberg CM, Friedlaender GE. The influence of ibuprofen on fracture repair: biomechanical, biochemical, histologic, and histomorphometric parameters in rats. J Orthop Res 1991;9:383-90.

14. Kilicoglu SS. Fracture healing at microscopy level. Ankara University Faculty of Medicine Journal 2002;55:143-50.

15. Echeverri LF, Herrero MA, Lopez JM, Oleaga G. Early stages of bone fracture healing: formation of a fibrin- collagen scaffold in the fracture hematoma. Bull Math Biol 2015;77:156-83.

16. Marsell R, Einhorn TA. The biology of fracture healing. Injury 2011;42:551-5.

17. Kolar P, Schmidt-Bleek K, Schell H, Gaber T, Toben D, Schmidmaier $G$, et al. The early fracture hematoma and its potential role in fracture healing. Tissue Eng Part B Rev 2010;16:427-34.

18. Montroy J, Hutton B, Moodley P, Fergusson NA, Cheng W, Tinmouth A, et al. The efficacy and safety of topical tranexamic acid: A systematic review and meta-analysis. Transfus Med Rev 2018:S0887-7963(17)30151-7.

19. Baldık Y, Talu U, Altınel L, Bilge H, Toker GA. Radiographic evaluation of the effect of nitric oxide on bone healing: an experimental study. Acta Orthop Traumatol Turc 2000;34:190-7.

20. Street J, Bao M, deGuzman L, Bunting S, Peale FV Jr, Ferrara $\mathrm{N}$, et al. Vascular endothelial growth factor stimulates bone repair by promoting angiogenesis and bone turnover. Proc Natl Acad Sci U S A 2002;99:9656-61.

21. Le Guehennec L, Goyenvalle E, Aguado E, Pilet P, Spaethe $\mathrm{R}$, Daculsi G. Influence of calcium chloride and aprotinin in the in vivo biological performance of a composite combining biphasic calcium phosphate granules and fibrin sealant. J Mater Sci Mater Med 2007;18:1489-95.

22. Yang ZG, Chen WP, Wu LD. Effectiveness and safety of tranexamic acid in reducing blood loss in total knee arthroplasty: a meta-analysis. J Bone Joint Surg [Am] 2012;94:1153-9.

23. Hofman M, Rabenschlag F, Andruszkow H, Andruszkow J, Möckel D, Lammers T, et al. Effect of neurokinin-1-receptor blockage on fracture healing in rats. Sci Rep 2019;9:9744.

24. Buarque de Gusmão CV, Batista NA, Vidotto Lemes VT, Maia Neto WL, de Faria LD, Alves JM, et al. Effect of LowIntensity Pulsed Ultrasound Stimulation, Extracorporeal Shockwaves and Radial Pressure Waves on Akt, BMP-2, ERK-2, FAK and TGF- $\beta 1$ During Bone Healing in Rat Tibial Defects. Ultrasound Med Biol 2019;45:2140-61.

25. Akyildiz S, Soluk-Tekkesin M, Keskin-Yalcin B, Unsal G, Ozel Yildiz S, Ozcan I, et al. Acceleration of Fracture Healing in Experimental Model: Platelet-Rich Fibrin or Hyaluronic Acid? J Craniofac Surg 2018;29:1794-8.

26. Schmidmaier G, Wildemann B, Heeger J, Gäbelein T, Flyvbjerg A, Bail HJ, et al. Improvement of fracture healing by systemic administration of growth hormone and local application of insulin-like growth factor-1 and transforming growth factor-beta1. Bone 2002;31:165-72.

27. Schoenecker J, Mignemi N, Stutz C, Liu Q, Edwards J, Lynch C, et al. 2010 Young Investigator Award winner: Therapeutic aprotinin stimulates osteoblast proliferation but inhibits differentiation and bone matrix mineralization. Spine (Phila Pa 1976) 2010;35:1008-16.

28. Çıraklı A, Gürgör PN, Uzun E, Erdem H, Çankaya S, Baş O. Local application of tranexamic acid affects tendon healing negatively in the late period. Eklem Hastalik Cerrahisi 2018;29:20-6.

29. Xie B, Tian J, Zhou DP. Administration of Tranexamic Acid Reduces Postoperative Blood Loss in Calcaneal Fractures: A Randomized Controlled Trial. J Foot Ankle Surg 2015;54:1106-10. 